\title{
Respiratory illnesses and ventilatory function among gem cutters in Sri Lanka
}

\author{
S Prathapan ${ }^{1}$, P Hettiarachchi², S W Wimalasekara ${ }^{2}$ \\ (Index words: gem cutters, Sri Lanka, pulmonary function tests, ventilatory function, spirometer)
}

\begin{abstract}
Introduction This study explores the proportion of respiratory symptoms and ventilatory functions among gem cutters in the city of gems, in Sri Lanka.

Methods All gem cutters in the Ratnapura Medical Officers of Health area were included and the control group was selected from the government officers residing in the same area. The gem cutters and the controls were matched according to their age and sex. Pulmonary function was measured with a spirometer and peak flow meter.

Results A significantly higher percentage of the exposed workers reported recurrent and prolonged cough (35\%) and chest tightening (10\%). $\mathrm{FEV}_{1}$ and $\mathrm{FEV}_{1} / \mathrm{FVC}$ was significantly lower in the exposed workers compared with unexposed workers. The results remained the same for the $\mathrm{FEV}_{1} / \mathrm{FVC}$ ratio $(p=0.004)$ after adjusting for age and body mass index.

Conclusions Adverse respiratory health effects observed among gem cutters were probably caused by exposure to gem dust.
\end{abstract}

Ceylon Medical Journal 2013; 58: 29-31

\section{Introduction}

Sri Lanka is, a country with an established industry of precious stone mining, mainly located in the 'city of gems', Ratnapura. $3.6 \%$ of the total population in the Ratnapura area is involved in the gem industry, of which $15 \%$ are gem cutters, earning $2 \%$ of the annual total exports revenue of the country.

The materials used to produce quality gems have been shown to affect the cardiovascular system and the respiratory system [1]. A higher incidence of respiratory diseases among these workers has been observed, such as occupational asthma and lung cancer in humans [2,3]. Inadequate or inappropriate preventive measures aggravate respiratory diseases. The health hazard and the risks have not been identified in the gem cutters in Sri Lanka. This preliminary study was performed to assess the lung function tests and to determine the job related health hazards of gem cutters.

\section{Methods}

This comparative cross sectional study was carried out in the Ratnapura Medical Officer of Health area. All gem cutters in this area were included. The control group was selected from the government offices of the same area and matched according to age and sex. Those below 18 years of age in both groups and people diagnosed with chronic respiratory diseases in the control group were excluded. The peak flow rate and lung function tests were measured using a peak flow meter and a spirometer respectively. The participants were trained and three measurements were recorded from each participant and the highest value was recorded. An interviewer administered questionnaire and calibrated standardised weighing scales and stadiometers were used. The human working hours was calculated from the time of recruitment. Approval was obtained from the Ethics committee of the University of Sri Jayewardenepura. Informed consent was obtained from the sample. Chi squared and tests were used to compare the two groups. Analysis of covariance was used to adjust the lung function tests for age and body mass index (BMI).

\section{Results}

The mean age of males and females were 31 years $( \pm 7.9)$ and 25 years $( \pm 6.4)$ respectively in both groups. All respiratory symptoms were found to be higher in the gem cutters than the controls (Table 1). $\mathrm{FEV}_{1}$ and $\mathrm{FEV}_{1} /$ FVC ratio was statistically significant between the two groups. The homogeneity of regression was analysed for all lung functions and found to be not statistically significant, which shows that there is no interaction between the covariates and each of the lung function tests. When adjusted for age and $\mathrm{BMI}$, the $\mathrm{FEV}_{1} / \mathrm{FVC}$ ratio was statistically significantly different between the gem cutters and the controls (Table 2). A statistically significant difference was found between each of the lung function tests and the working hours (Table 3).

Departments of ${ }^{1}$ Community Medicine and ${ }^{2}$ Physiology, Faculty of Medical Sciences, University of Sri Jayewardenepura, Sri Lanka.

Correspondence: SP, email: <drpbshamini@yahoo.com>. Received 25 July and revised version accepted 25 October 2012. Competing interests: none declared. 
Table 1. Gem cutters and controls

\begin{tabular}{|c|c|c|c|}
\hline & $\begin{array}{c}\text { Gem cutters } \\
\text { No }(\%)\end{array}$ & $\begin{array}{l}\text { Controls } \\
\text { No (\%) }\end{array}$ & $p$ value \\
\hline \multicolumn{4}{|l|}{ Sex } \\
\hline Females & $44(58.7)$ & $31(41.3)$ & 0.23 \\
\hline Males & $49(49.5)$ & $50(50.5)$ & \\
\hline \multicolumn{4}{|l|}{ BMI $\left(\mathrm{Kg} / \mathrm{m}^{2}\right)$} \\
\hline Underweight & $17(53.1)$ & $15(46.9)$ & \\
\hline Normal & $49(44.1)$ & $62(55.9)$ & 0.65 \\
\hline Obese / overweight & $15(48.4)$ & $16(51.6)$ & \\
\hline \multicolumn{4}{|l|}{ Respiratory symptoms } \\
\hline Cough & $51(34.7)$ & $29(19.7)$ & 0.01 \\
\hline Wheezing & $18(12.2)$ & $9(6.1)$ & 0.10 \\
\hline Nasal block & $43(29.3)$ & $32(21.8)$ & 0.18 \\
\hline Chest tightening & $14(9.5)$ & $4(2.7)$ & 0.03 \\
\hline Difficulty in breathing & $17(11.6)$ & $8(5.4)$ & 0.09 \\
\hline Sneezing & $47(32.0)$ & $35(23.8)$ & 0.15 \\
\hline
\end{tabular}

Table 2. Comparison of lung function tests among gem cutters and controls

\begin{tabular}{|c|c|c|c|c|c|c|c|}
\hline & \multicolumn{2}{|c|}{ Gem cutters } & \multicolumn{2}{|c|}{ Controls } & \multirow[t]{2}{*}{$p$ value } & \multirow{2}{*}{$\begin{array}{l}\text { Adjus- } \\
\text { ted } \\
\text { F ratio }\end{array}$} & \multirow{2}{*}{$\begin{array}{l}\text { Adjus- } \\
\text { ted } \\
p \text { value }\end{array}$} \\
\hline & Mean & $S D$ & Mean & $S D$ & & & \\
\hline $\mathrm{FEV}_{1}$ & 2.14 & 0.71 & 2.34 & 0.78 & 0.02 & 1.8 & 0.17 \\
\hline FVC & 2.50 & 0.82 & 2.62 & 0.82 & 0.24 & 1.7 & 0.85 \\
\hline $\mathrm{FEV}_{1} / \mathrm{FVC}$ & 80.63 & 11.59 & 90.0 & 9.69 & 0.01 & 8.4 & 0.004 \\
\hline PEFR & 373.16 & 110.47 & 381.7 & 107.01 & 0.50 & 1.8 & 0.172 \\
\hline
\end{tabular}

Table 3. Correlation between lung function tests and human working hours

\begin{tabular}{lcc}
\hline $\begin{array}{c}\text { Lung function } \\
\text { tests }\end{array}$ & $\begin{array}{c}\text { Pearson correlation } \\
\text { coefficient }\end{array}$ & $p$ value \\
\hline FEV $_{1}$ & 0.18 & $\mathbf{0 . 0 3}$ \\
FVC & 0.29 & $\mathbf{0 . 0 0}$ \\
FEV $/$ FVC & -0.23 & $\mathbf{0 . 0 1}$ \\
PEFR & 0.30 & $\mathbf{0 . 0 0}$ \\
\hline
\end{tabular}

\section{Discussion}

This study, the first in the Sri Lankan precious stone industry, was a base line study, initiated to identify potential health hazards in gem cutters. The strength of the study was that the total study population was included into the study. The healthy worker effect has to be considered which may bias our results towards underestimation of potentially adverse health effects. The healthy worker effect could not be taken into consideration due to unavailability of data of those who had left their jobs due to various health problems.

Cough (35\%) and chest tightening (9\%) were statistically significant $(p<0.05)$ in the gem cutters than in the controls. Lung diseases have been reported in jewelers who use asbestos as and silica $[4,5]$. Respiratory cancer in silica gem cutters was not found to be a common occurrence in some cohorts [6,7]. No adverse clinical health effects were associated with beryllium [8]. However diamond polishers showed decreased pulmonary function $\left(\mathrm{FEV}_{1}\right.$ and $\left.\mathrm{FVC}\right)$ due to exposure to cobalt [9].

In gem cutters $F E V_{1}$ was significantly low, compared to controls. FVC was also reduced although not significantly compared to controls. Both $\mathrm{FEV}_{1}$ and FVC have reduced proportionately. The extent of the reduction in $\mathrm{FEV}_{1} / \mathrm{FVC}$ ratio however is within the normal range of over $70 \%$ and significantly lower than the control group. Similar changes indicating early loss of respiratory function have been observed in other studies too [10]. The low $\mathrm{FEV}_{1} / \mathrm{FVC}$ ratio in the gem cutters is statistically significant after adjusting for age and BMI. This implies that the exposure to dust during gem cutting makes the workers more prone to a restrictive respiratory disease.

Lung function tests and the working hours, although found to be significantly different, had moderate correlation (Table 3). Further analysis is needed to define the pattern of the existing relationship. Airborne metal concentrations above the threshold limit values could be a causative factor. Longitudinal or cohort studies are recommended. Steps should be taken by the health planners to modify the working environment.

\section{Acknowledgements}

We thank D V T Madhurangi, M N Costa, N A D Priyadarshani, W G D Dimuthumali, W H A M S Piyadasa, AA Jeewani, K L Madhuka, H M N Priyadarshani, B W T $\mathrm{U}$ Kulathunga and $\mathrm{K} \mathrm{M} M$ Faheema for all support in formulation of the research project and data collection. We thank the IRQUE fund for supporting this research project. 


\section{References}

1. Tiwari RR, Saha A, Parikh JR. Respiratory morbidities among working children of gem polishing industries, India. Toxicology and Industrial Health 2009; 25: 81-4.

2. White NW, Chetty R, Eric D. Bateman. Silicosis among gemstone workers in South Africa: Tiger's-eye pneumoconiosis. American Journal of Industrial Medicine 2007; 19: 205-13.

3. Huang Li-rong, Chen Su-sheng, LI Jun-hui, et al. Study on pulmonary functions in 53 patients with gem's silicosis. Chinese Occupational Medicine 2004; 3: 9.

4. Kern DG, Hanley KT, Roggli VL. Malignant mesothelioma in the jewelry industry. American Journal of Industrial Medicine 1993; 21: 409-16.

5. Dossing M, Langer SM. Asbestos-induced lung injury among Danish jewelry workers. American Journal of Industrial Medicine 1994; 26: 755-8.
6. Wegner R, Heinrich-Ramm R, Nowak D, Olma K, Poschadel $\mathrm{B}$, Szadkowski D. Lung function, biological monitoring, and biological effect monitoring of gemstone cutters exposed to beryls. Occupational and Environmental Medicine 2000; 57: 133-9.

7. Sparks PJ, Wegman D. Cause of death among jewelry workers. Journal of Occupational Medicine 1980; 22: 733- 6.

8. Hayes RB, Dosemeci M, Riscigno M, et al. Cancer mortality among jewelry workers. American Journal of Industrial Medicine 1993; 24: 743-51.

9. Ng TP, Tsin TW, O'Kelly FJ, Chan SL. A survey of the respiratory health of silica-exposed gemstone workers in Hong Kong. The American Review of Respiratory Disease 1987; 135: 1249-54.

10. Ghotkar VB, Maldhure BR, Zodpey SP. Involvement of Lung and Lung Function Tests in Stone Quarry Workers. The Indian Journal of Tuberculosis 1995; 42: 155-60.

\title{
Kikuchi-Fujimoto's disease: a case series from Sri Lanka
}

\author{
R A Abeysekera ${ }^{1}$, S A M Kularatne ${ }^{2}$, R Waduge $^{3}$, A G W Sandeepana ${ }^{1}$, J M R P Bandara ${ }^{1}$, \\ I V B Imbulpitiya ${ }^{1}$
}

(Index words: Kikuchi-Fujimoto's disease, necrotising lymphadenitis)

\begin{abstract}
Introduction Kikuchi's disease is a rare, benign, selflimiting disease, mainly involving the lymph nodes of young people. The etiology is unknown. Clinical symptoms and basic investigations may mimic lymphomas and chronic granulomatous conditions like tuberculosis. Lymph node biopsy shows characteristic diagnostic features. Even though described internationally, the local disease pattern or incidence has not been well studied. Methods We studied all patients who were diagnosed with Kikuchi's disease at Teaching Hospital, Peradeniya from January 2011 to April 2012.

Results A total of 9 cases showed histopathological features of Kikuchi's disease. All patients were females, in the age group of 12-30 years having fever and lymphadenopathy. They carried a provisional diagnosis of lymphoma, tuberculosis or reactive lymphadenitis.
\end{abstract}

Conclusions Necrotising lymphadenitis has a predilection for cervical lymph nodes of females and is usually accompanied by fever. Clinical features can resemble tuberculous lymphadenitis or malignant lymphoma. Excision biopsy of the involved node is mandatory for the diagnosis.

Ceylon Medical Journal 2013; 58: 31-33

\section{Introduction}

Histiocytic necrotising lymphadenitis was first described independently in 1972 by Kikuchi and Fujimoto from Japan [1,2]. Hence, the entity is also known as KikuchiFujimoto's disease or simply Kikuchi's disease (KD). It classically presents as a painful cervical lymphadenopathy in young adults, usually females. Unilateral involvement of the posterior cervical group is the commonest picture.

${ }^{1}$ Medical Unit, Teaching Hospital Peradeniya, Departments of ${ }^{2}$ Medicine and ${ }^{3}$ Pathology, Faculty of Medicine, University of Peradeniya, Sri Lanka.

Correspondence: RAA, email: <rajithaasa5@hotmail.com>. Received 10 July and revised version accepted 11 October 2012. Competing interests: none declared. 